\title{
Upper Gastrointestinal Bleeding Due to Haemobilia
}

\author{
Lamichhane $\mathbf{R}^{1}$, Joshi BG ${ }^{2}$, Wadhwa ${ }^{3}$, Gupta A $^{4}$ \\ ${ }^{1}$ Dr. Ritu Lamichhane, MBBS. MD. Registrar, Department of Pediatrics, Norvic International Hospital, Kathmandu, Nepal. \\ ${ }^{2}$ Dr. Binita G. Joshi, MBBS. MD. ${ }^{3}$ Consultant Paediatric Gastroenterologist, Norvic International Hospital, Kathmandu, Nepal.
}

Dr. Nishant Wadhwa, MBBS, DNB, Consultant Gastroenterologist, Sir Gangaram Hospital, New Delhi, India, ${ }^{4}$ Dr. Arun Gupta, MBBS. DNB, Consultant Interventional Radiologist, Sir Gangaram Hospital, New Delhi.

Address for correspondence:

Dr. Ritu Lamichhane

E-mail: reetu7731@gmail.com

\section{How to cite}

Lamichhane R, Joshi BG, Wadhwa N, Gupta A. Upper Gastrointestinal Bleeding Due to Haemobilia. J Nepal Paediatr Soc 2016;36(1):100-102

doi: http://dx.doi.org/10.3126/jnps.v36i1.14569

This work is licensed under a Creative Commons Attribution 3.0 License.

\begin{abstract}
Haemobilia is one rare but potentially life threatening complication of delayed haemorrhage following liver trauma which occurs as a result of pathological communication between bile ducts and intra or extrahepatic vessels. We describe here a case of two year old child who presented with upper gastrointestinal bleeding and developed haemobilia in one month duration after blunt abdominal trauma. CT angiography revealed a right hepatic artery pseudo aneurysm as the cause of haemobilia and was successfully treated with right hepatic artery embolisation.
\end{abstract}

Key words: embolisation, haemobilia, pseudo aneurysm, upper gastrointestinal bleeding,

\section{Introduction}

$\mathrm{D}$ elayed complications from blunt liver trauma can occur from weeks to months after the trauma and may include delayed haemorrhage, post traumatic pseudo aneurysm, abscess, hematoma and biliary complications ${ }^{1}$. Haemobilia is a rare cause of upper gastrointestinal bleeding which needs prompt diagnosis and immediate management to save life. Posttraumatic pseudo aneurysm of hepatic artery is seen in $1 \%$ of hepatic injury. It should be considered in patients presenting with upper gastrointestinal bleeding with prior history of abdominal trauma. Patients commonly present with either haematemesis or melina but may also present with abdominal pain or jaundice. Diagnosis requires a high index of suspicion and angiography should be performed when suspected ${ }^{2}$. These are successfully treated with endovascular embolisation.

\section{The Case}

A two year old boy presented with history of haematemesis and melina for two days. He had history of blunt abdominal trauma by metal pipe four weeks earlier. Patient underwent exploratory laparotomy and peritoneal lavage with drainage of about 30-40 ml blood and was managed conservatively with intravenous fluids, antibiotics and blood transfusion. He was sent home after 13 days of hospital stay.

After two weeks of discharge from hospital, he had two episodes of haematemesis and melina. Upon examination, he was pale, slightly 
icteric, and haemodynamically stable with slight tender abdomen and hepatomegaly. His hemoglobin was 8 gm\%, SGPT, SGOT and bilirubin levels were raised. WBC, platelet count, PT, APTT, electrolytes were all normal. Ultrasound abdomen showed old hematoma in liver and gall bladder sludge/clot. He was referred to our centre for Upper GI endoscopy which was normal. He was treated with intravenous fluids and antibiotics.

A CECT scan was advised which showed contusion in right lobe of liver with minimal adjacent subcapsular hematoma, pseudo aneurysm of right hepatic artery, haemobilia in gall bladder, mildly dilated intrahepatic ducts and minimal ascites. He was then immediately referred to India for further management due to lack of paediatric interventional expertise at our centre.

Patient was admitted in Intensive Care Unit. On examination, he had severe anemia, hepatomegaly and signs of bleeding. Paediatric gastroenterology reference was taken and managed with intravenous fluids, antibiotics and blood transfusion. CT angiography was suggestive of pseudo aneurysm of right hepatic artery, haemobilia, laceration in right lobe of liver. He then underwent right hepatic artery embolization. Post embolization, child remained haemodynamically stable. Haematological parameters remained stable through his PICU stay post embolization. He was discharged after 6 days of hospital stay with oral antibiotics and vitamins.

On his follow up after two weeks, there was no recurrence of bleeding, had gained weight and haematological parameters were normal.

\section{Discussion}

Haemobilia is defined as bleeding into the biliary tree from abnormal communication between blood vessel and bile duct ${ }^{3}$. Mean time period between traumatic hepatic injury and presentation of patient with haemobilia is four weeks ${ }^{1,3}$. Most common cause of post traumatic haemobilia is described as pseudo aneurysm ${ }^{3}$. Hepatic artery pseudo aneurysm is a pulsatile hematoma due to leakage of blood through a tear or disruption of arterial wall $^{4}$. The causes include medical procedures, trauma, infectious and inflammatory conditions ${ }^{5}$. Bile leaks have been associated with pseudo aneurysm due to close proximity of vessels to the biliary system ${ }^{6}$. Haemorrhage from hepatic pseudo aneurysm is life threatening with a mortality rate of $9 \%$ in a recent series ${ }^{5}$. If not diagnosed early, can lead to massive gastrointestinal haemorrhage due to haemobilia and aortoenteric fistulas ${ }^{7}$.
The mode of presentation to some extent depends on the size of pseudo aneurysm as larger ones have greater risk of rupture ${ }^{8}$. Classical clinical manifestation of haemobilia constitutes Quinke's triad of symptoms, consisting of abdominal pain (70\%), UGI bleeding ( $90 \%$ melena, $60 \%$ haematemesis), jaundice (60\%). However the whole triad is present in $22-30 \%$ of patients only with haemobilia $2,5,7,9,10$. In our patient, all three symptoms were present.

Haemobilia is difficult to diagnose since the bleeding is usually intermittent ${ }^{9}$. The initial investigation is usually UGI endoscopy which may reveal altered blood or clots in stomach and duodenum but without apparent source of active bleeding or may directly reveal blood flowing out of papilla of Vater. It may also rule out other causes of bleeding such as erosive gastritis, ulcers and varices ${ }^{8,11}$. Abdominal ultrasound can be useful in diagnosis of haemobilia but is nonspecific wherein Doppler ultrasound can be useful in detecting aneurysm or pseudo aneurysm of hepatic artery ${ }^{9}$. The gold standard diagnostic investigation is angiography ${ }^{5,9}$ which can show presence of arteriobiliary fistula and vascular malformations like aneurysm, pseudo aneurysm and haemangiomas as well as can delineate the arterial anatomy and site of pseudo aneurysm for therapeutic intervention ${ }^{9}$. However CECT is currently the diagnostic modality of choice ${ }^{1,3,9}$. Haemobilia may cause CT scan finding of mixed or uniform high attenuation blood within gallbladder lumen as well as may reveal dilatation of bile ducts and gall bladder ${ }^{3}$. MRI has also been shown to depict presence and extent of pseudoaneurysm accurately ${ }^{4}$.Overall diagnosis of haemobilia requires a high index of suspicion in patients with gastrointestinal bleeding $2,3,7,8$.

Owing to high risk of potential complications like rupture and associated haemorrhage or enteric fistulisation $^{4}$, therapeutic options available are endovascular embolization and open surgery, 4,5,9,12,13,14. Endovascular embolisation has become the first line of treatment and has shown to be effective and safe with decreased morbidity than surgery in young children. Hepatic artery embolisation involves the selective catheterisation of a branch of the hepatic artery followed by use of embolic agents including autologous blood clot, balloons, coils, cyanoacrylate or gelatine sponge. Good results have been achieved in $80-100 \%$ of cases $^{5,10}$. Historically pseudo aneurysm have been treated with lobectomy however currently, surgical treatment is indicated in patients with hemodynamic instability, failed angio embolisation and for cases requiring laparotomy $y^{6,9}$ 


\section{Conclusion}

Development of delayed upper GI bleeding after blunt abdominal trauma should give rise to a clinical suspicion of possible haemobilia and the underlying hepatic artery pseudo aneurysm and should prompt confirmation with endoscopy, CECT and angiography. Angioembolisation is the best available treatment option. Though morbid, surgery is lifesaving in cases of failed angioembolisation.

\section{References}

1. Francisco LE, Asunción LC, Antonio CA, Ricardo RC, Manuel RP, Caridad MH. Post-traumatic hepatic artery pseudoaneurysm treated with endovascular embolization and thrombin injection. World $J$ Hepatol 2010;27;2(2): 87-90.

2. Negi RC, Sharma B, Bhupender, Kapoor G, Verma $B B$, Sharma A. A rare cause of upper gastrointestinal bleeding: Posttraumatic pseudoaneurysm. Int J Case Rep Imag 2014;5(5):387-390.

3. Wani NA, Gojwari TA, Khan NA, Kosar TL. Hemobilia in a child due to right hepatic artery pseudoaneurysm: Multidetector-row computed tomography demonstration. Saudi J Gastroenterol 2011;17(2):152154. doi: $10.4103 / 1319-3767.77250$

4. Basile KE, Sivit CJ, Sachs PB, Stallion A. Hepatic arterial pseudoaneurysm: a rare complication of blunt abdominal trauma in children. Pediatr Radiol 1999;29(5):306-8.

5. Luo X, Tan S, Wang J, Qian C. Upper gastrointestinal hemorrhage from hepatic artery pseudoaneurysm secondary to trauma: a case report. Med Princ Pract 2010;19(6):493-5. doi: 10.1159/000320311. Epub 2010 Sep 28

6. Choi PM, Desmarais TJ, Keller MS. Late complications after blunt liver injury in a child: Hemobilia with pseudoaneurysm, hemocholecystitis and biloma. J Pediatr Surg Case Rep 2014;30;2(4):162-5.

7. Bishehsari F, Ting PS, Green RM. Recurrent gastrointestinal bleeding and hepatic infarction after liver biopsy. World J Gastroenterol 2014;21;20(7):187881. doi: $10.3748 /$ wjg.v20.i7.1878.
8. Khan MR, Raza R, Salam B. Leaking pseudoaneurysm of hepatic artery: a potentially life-threatening complication of a common procedure. J Pak Med Assoc 2011;61(5):504-6

9. Murugesan SD, Sathyanesan J, Lakshmanan A, Ramaswami S, Perumal S, Perumal SU, Ramasamy R, Palaniappan R. Massive hemobilia: a diagnostic and therapeutic challenge. World J Surg 2014;38(7):175562. doi: 10.1007/s00268-013-2435-5.

10. Queiroz HM, Costa FD, Campos Junior MM, Aquino $\mathrm{RL}$, Linhares Filho FA, Otoch M. Arterial embolization in the treatment of hemobilia after hepatic trauma: a case report. Radiol Bras 2012 Feb;45(1):63-4.

11. Sebastian JJ, Peña E, Blas JM, Ceña G. Fatal upper gastrointestinal bleeding due to hepatic artery pseudoaneurysm diagnosed by endoscopy. Dig Dis Sci 2008;53(4):1152-3.

12. Kamath V, Gunabushanam V, Hanna A, Siegel D, Sung C, Dolgin SE. Life-threatening postoperative hemorrhage from hepatic artery pseudoaneurysm successfully treated by transcatheter embolization in a 5-year-old. J Pediatr Surg 2012;47(3):585-7. doi: 10.1016/j.jpedsurg.2011.12.008.

13. Mate $A D$, Surnare KR, Deolekar SS, Gvalani AK. Lower gastrointestinal bleeding due to hepatic artery pseudoaneurysm following laparoscopic cholecystectomy. J Minim Access Surg 2013;9(1):313. doi: 10.4103/0972-9941.107135.

14. Laing GL, Clarke DL, Ferndale L, Reitz D, Manchev V. Haemobilia following blunt liver injury. S Afr J Surg 2012;12;50(4):136-7. doi: 10.7196/sajs. 1442. 